\title{
Stochastic Medium Model of Ground Surface Movements due to Foundation Excavation
}

\author{
Yue-Guang $\mathrm{HE}^{1, \mathrm{a},{ }^{,} \text {, Meng } \mathrm{ZHOU}^{1, \mathrm{~b}} \text {, Lei-Sen SHAO }}{ }^{1, \mathrm{c}}$ \\ ${ }^{1}$ Changsha University of Science and Technology, School of Communication and Transportation \\ Engineering, Changsha 410004, China \\ ahyg@csust.edu.cn, b1121874907@qq.com, 544012001@qq.com \\ ${ }^{*}$ Corresponding author
}

Keywords: Engineering Excavation, Ground Surface Movements and Deformation, Stochastic Medium Theory, Monitoring.

\begin{abstract}
Stochastic medium model belongs to in-continuous medium theory. Open-pit slope and the slope are important excavation project that human utilize nature. In this paper, stochastic medium model was used in the foundation pit engineering ground surface movements. The adjacent ground surface movement and deformation due to dewatering and around body losing cross bloster is analyzed.

Since any excavation will cause the surrounding surface movement and deformation, however, any ground and underground construction (structures) have certain structural strength, which has a certain resistance to the ground displacement and deformation capacity [1]. If the deformation of the ground is expected that the results were less than the maximum permitted Level protection of building structures deformation value, the building structures will not change significantly damage, or can be made by a simple process and does not affect the normal use; if the deformation of the ground the results are expected to exceed the maximum allowable Level protection of building structures deformation value, you can take the reinforcement of building structures, prereinforcement measures or adjust excavation programs to achieve conservation purposes. People study model of surface movement and deformation is caused by excavation, especially from the gravity stress research underground coal mining began from underground mines. In China, the study of surface coal movement law has made considerable progress in the establishment based on probability integration method, negative exponential function method and the typical curve of surface deformation prediction methodology. Which is particularly widespread application of probability integration method, which greatly promoted the development of the cause of the "three under mining," and China's entry into the list of international advanced in this area, $[2,3,4,5]$.
\end{abstract}

\section{Movement and Deformation Grade}

In 1950s, the polish scholars on the basis of previous studies, put forward are shown in table 1 of the standard of surface movement and deformation.

Tab. 1 Poland Criteria for the Classification of Surface Movement and Deformation

\begin{tabular}{|c|c|c|c|}
\hline Classification & Inclined $(\mathrm{mm} / \mathrm{m})$ & $\begin{array}{c}\text { Horizontal } \\
\text { Deformation }(\mathrm{mm} / \mathrm{m})\end{array}$ & Curvature $(1 / \mathrm{m})$ \\
\hline I & $\leq 2.5$ & $\leq 1.5$ & $\leq 50 \times 10^{-6}$ \\
II & $\leq 5.0$ & $\leq 3.0$ & $\leq 83 \times 10^{-6}$ \\
III & $\leq 10.0$ & $\leq 7.0$ & $\leq 166 \times 10^{-6}$ \\
IV & $\leq 15.0$ & $\leq 9.0$ & $\leq 250 \times 10^{-6}$ \\
\hline
\end{tabular}

In China, the former Ministry of Coal Industry in the 1960s pioneered the development of China's first underground mining ground surface to protect building structures and other objects 
protection grading standards, and promulgated in 1985's "buildings, water, rail and major roadway Pillar leaving in coal mining regulations and the pressure, "according to the importance of buildings and structures, uses and different consequences caused by the impact of mining, the protection level is divided into four levels.

\section{Stochastic Medium Theory and the Suitable Conditions}

Stochastic medium theory first by the Polish scholar J.Litwinisyn introduced rock movement in the 1950s, Chinese scholars Liu Baochen depth research and development as the probability integral method $[8,9]$. J.Litwinisyn and other scholars application of non-continuum mechanics granulosis mechanics to study rock and ground movement problems, they thinks that the law of strata and ground movement caused by the mining similar as the law of stochastic medium granule medium model in the macroscopic. Probability integral calculation method is to rock and ground movement caused by underground mining process looking to a random process, Establishment rock and surface caused by underground unit mining unit subsidence basin expressions and unit horizontal movement expression with probability theory, Established profile equations and other mobile surface subsidence and deformation distribution of expression by the superposition.

As shown in Fig 1, In the Cartesian coordinate system, $z x, z \xi, z \eta$ representing different strata level. Finally subsidence basin $\mathrm{W}$ satisfies the equation:

$$
\frac{\partial W(z, x)}{\partial z}=\alpha(z, x) W(z, x)+\beta(z, x) \frac{\partial W(z, x)}{\partial x}+\gamma(z, x) \frac{\partial^{2} W(z, x)}{\partial x^{2}}
$$

By the formula (1) can be obtained from horizontal layers or levels of isotropic medium, Unit subsidence basin expression is:

$$
W_{e}(x, y, z)=\frac{1}{r^{2}(z)} \bullet \exp \left[-\frac{\pi}{r^{2}(z)}\left(x^{2}+y^{2}\right)\right]
$$

$r$ is the main impact of radius in the formula. $r=\frac{\sqrt{\pi}}{h}$.

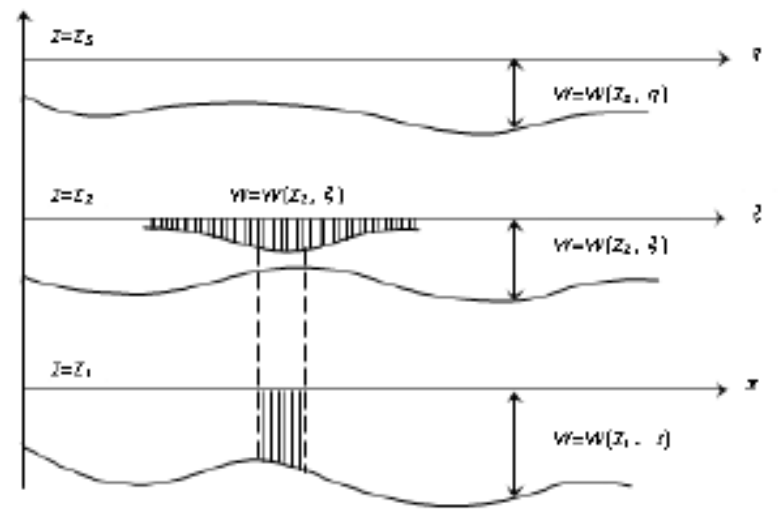

Fig. 1 Transfer of Mining Influence

For the surface, $z$ is equal to the mining depth, $B(z)$ is a constant, can make to $Z$, then

$$
U(x)=B \bullet \frac{d W_{e}(x)}{d x}=\frac{2 \pi B x}{r^{3}} \exp \left\lfloor-\pi \frac{x^{2}}{r^{2}}\right\rfloor
$$

Formula (3) is the expression of surface unit mining movement. Based on the above derivation, we can obtain the value of surface movement and deformation at any level of exploitation. 
The following analysis of stochastic medium theory to adapt to the conditions in the others field of engineering excavating surface movement predict.

\section{The Tectonic Stress Surface Subsidence Mining Law}

Whether steeply inclined caving method mining metallurgical and mining or caving method mining inclined coal, its mining subsidence belong to "surface movement under the tectonic stress." The common point is: Surface mining subsidence at the same time by the weight of stress, but also by the tectonic stress, as well as disposable seam dip size, the degree of development of jointed rock roof and structure, mining methods and ore drawing laws. When mining tectonic stress significant, tectonic stress will change the shape of surface subsidence of the basin, and to dramatically expand the scope of subsidence of the basin, and even the shaft and industrial plaza falling into the destruction area and unable to continue mining.

Under the deadweight stress surface movement as the basis for research,after removing the deadweight stress component component referred to as tectonic stress. Of a ore block or a mining area mined, In the formation of surface subsidence pits on the surface influencers should be general changed stress, it is a dynamic concept with engineering changes, and controlled by geological rock, Deadweight stress excavation unloading affect export generic coal regularity of surface movement, Excavation under general changed stress conditions generalized to unload it changes the deadweigh stress unload a single mode of action, and can be transformed into stochastic medium theory pure geometry Kinematic Study to improve the surface subsidence mode to overlay on the inclination affected.

Therefore, we can combine steeply inclined caving method mining metallurgical and mining or caving method mining inclined coal practice, By tilt angle, tectonic stress, geological conditions and broken morphology, mining methods and ore drawing laws to establish the corresponding influence Function, mathematical models, predicted equation, to determine the surface movement law under the tectonic stress, improve stochastic theory.

\section{Surface Movement Caused by Slope and Foundation Pit Engineering Excavation}

The open-pit mining slope and Foundation Pit excavation will make rock and soil mass hydrophobicity, leading geotechnical body falling water tables, while the excavation of rock and soil mass lose some lateral bracing, slope and Foundation Pit side walls of rock and soil mass will be excavated pit space to produce movement, Rock and soil mass hydrophobic backbone of effective stress will increase, causing the Rock and Soil compressive consolidation, resulting in subsidence and deformation of rock and soil mass slope. Slope rock and soil mass subsidence and deformation caused by hydrophobic, often greater than the subsidence and deformation caused by the excavation itself $[10,11]$.

Slope Engineering. Typically, Researcher multi-use limit equilibrium analysis method, the Monte Carlo method, engineering analogy, rock mass structure analysis method the natural slope statistics method, and similarity simulation method to study the open pit slope. In the production process of practice, if not control the slope sliding of directional structure weak surface, rock stochastic fracture development or weathered significant. And although steady but neighbors by industrial plants and civil buildings cases significantly the mining damage or even destroy, you can use the stochastic medium theory research of surface movement and deformation of the excavation under the influence.

Foundation Pit Engineering. With the size and excavation pit depth increases, In addition to making the temporary retaining structure deformation and stability become very concerned about the problem in engineering circles. Because of all types of buildings intensive increases in cities, the adjacent environment, underground pipelines, ground transportation to the surface deformation after excavation and construction generated became more stringent

The Foundation Pit excavation will make rock and soil mass hydrophobicity, leading geotechnical body falling water tables, while the excavation of rock and soil mass lose some lateral bracing, Foundation Pit side walls of rock and soil mass will be excavated pit space to produce 
movement, Rock and soil mass hydrophobic backbone of effective stress will increase, causing the Rock and Soil compressive consolidation, resulting in subsidence and deformation of rock and soil mass slope. Stochastic medium theory and rock consolidation theory can be comprehensive study of surface movement and deformation caused by Foundation Pit excavation and hydrophobic.

Let deep foundation pit excavation support for bored pile and inside support of excavation, foundation pit excavation width is $2 M$, length is $2 \mathrm{~N}$, excavation depth is $h$, bored pile depth is $H_{0}$. After inside support has been added, Pressure acts affect by the excavation losing side, the deep foundation pit filling pile of the pile deflection curve and the top of the pile wall horizontal displacement curve can be fitted with a parabola. The large number of the measured data statistical analysis, rectifiable the deep the pile deflection curve and the horizontal displacement of the pile wall curve equation.

According to stochastic medium theory, Can be determined the distribution of surface subsidence around the foundation pit. When the let maximum subsidence value $S(\xi, \zeta, \eta)=h$, surface subsidence is:

$$
W(x, y)=h \bullet \int_{a}^{b} \frac{1}{R} \exp \left[-\frac{\pi}{R^{2}}(x-\xi)^{2}\right] d \xi \int_{c}^{d} \frac{1}{R} \exp \left[-\frac{\pi}{R^{2}}(y-\zeta)^{2}\right] d \zeta
$$

Where $a, b, c, d$ were deformation range caused by excavation respectively.

Accordingly can be determined the peripheral surface of horizontal movement and deformation caused by foundation pit excavation. After considering lowering the groundwater level, you can determine the corresponding ultimate surface movement and deformation values.

\section{Surface Movement Caused by Urban Underground Engineering Excavation}

Deformation characteristics of urban underground engineering,Physical structure, the initial stress field distribution, effects of temperature and water erosion, etc. many respects has obvious heterogeneities discrete nature non-continuous and non-linear characteristics, resulting in the construction of underground architecture, the use phase exhibit fairly unique and complex mechanical properties. Its security, economic and the normal use is closely related to the located engineering geological environment. Due to destruction of underground engineering Rock mass initial equilibrium conditions, causing the body of stress redistribution rock, except for a few particularly good geological conditions and rock strength to adapt to this change of the stress condition, the surrounding rock will often produce a variety of forms deformation, damage, especially severe cases may have been affect to the surface.

Urban underground engineering influence of excavation refers surrounding rock movement and ground surface subsidence caused by excavation, Surface subsidence caused by tunnel excavation, which generally showed basin-shaped cross section, can be used to describe the probability integral. For shallow surface subsidence caused by buried-type tunnel excavation, Its maximum subsidence by the following three aspects: subsidence before excavation support;subsidence caused by underground drainage pumping;subsidence after excavation support; The surface movement and deformation caused by rock and soil underground excavation for stochastic medium theory expected can achieve high accuracy.

\section{Conclusion}

For the surrounding surface movement and deformation caused by excavation, resulting in the adjacent building (structure) $\mathrm{s}$ and environment hazards that may arise, the monitoring techniques is to achieve prevention, and an important means of avoiding disaster and post-processing. By analyzing stochastic medium theory generate basic and application characteristics, surface building structures movement and deformation level and allow deformation values, we obtained:

(1) The tectonic stress type of mines can change stochastic medium theory expect the surface damage characteristics; 
(2) If not control the slope sliding of directional structure weak surface, rock stochastic fracture development or weathered significant. And although steady but neighbors by industrial plants and civil buildings cases significantly the mining damage or even destroy, You can use the stochastic medium theory research of surface movement and deformation of the excavation under the influence.

(3) Urban underground engineering influence of excavation refers surrounding rock movement and ground surface subsidence caused by excavation, Surface subsidence caused by tunnel excavation, which generally showed basin-shaped cross section, can be used to describe the probability integral.

(4) The adjacent ground surface movement and deformation due to dewatering and around body losing cross bloster is analyzed.

\section{References}

[1]Ning Jinsheng. Introduction to Geomatics. wuhan: wuhan university press, 2004.

[2]Qie Qihu. Chinese Journal of Geotechnical Engineering, 1998, 20(1), 112- 113.

[3]Apehc B A. Rock and Ground Surface Movements. Beijing: Coal industry Press, 1989.

[4]J.Litwinisayn. The theories and model research of ground.Collery eng. 1985(10).

[5]New B M,Bowers K H.Ground movement model validation at the heathrow express trial.Tunnelling, 1994, (3):301- 329.

[6]Liu Baochen and Yong Junsheng.Coal Journal, 1999, 24(1): 39- 42.

[7]Liu Baochen.Ground surface movement due to underground excavation in the P.R.China.Comprehensive rock engineering.Vol.4, Pergaman Press, 1993.

[8]Liu Baochen.Chinese Journal of Rock Machanics and Engineering, 1999, 18(1), 109- 111.

[9]Liu Baochen and Liao Guohua.Coal Mining Ground Surface Movements.Beijing:Chinese industry Press, 1965.

[10]E.Hoek,E.T.Brown.Underground Excavation in Rock.Beijing: Metallurgical Press, 1986.2.

[11]New B M,Bowers K H.Ground movement model validation at the heathrow express trial.Tunnelling, 1994, (3):301- 329. 